\title{
EFFECTS OF A HARSH ENVIRONMENT ON THE LIFE HISTORY PATTERNS OF TWO SPECIES OF TROPICAL AQUATIC HEMIPTERA (FAMILY: NAUCORIDAE) ${ }^{1}$
}

\author{
R. JEAN STOUT ${ }^{2}$ \\ Division of Biological Sciences, University of Michigan, \\ Ann Arbor, Michigan 48109 USA
}

\begin{abstract}
The relative abundances and distribution patterns for two species of aquatic predaceous creeping water bugs (Family: Naucoridae) were determined for two tropical streams at Finca La Selva, Costa Rica, from July 1975 to August 1977. Seasonal changes in population densities were found to be related to differential recruitment and dispersal patterns for the two populations. Extreme population losses for both species occurred during flood periods in one of the two streams. Heavy rains in the mountainous watershed, which can occur 15-30 times/yr, caused one stream, the Sabalo, to spate, and it was in that stream that populations of both species were negatively affected during spates. The second stream, the Sura, is a low-gradient tropical stream and it is backflooded by a large river, the Puerto Viejo. During backfiooding, there are reductions in dissolved oxygen and in velocity, but the changes do not affect these plastron-breathing insects. Although depths in both streams increase up to $9 \mathrm{~m}$ during flooding, the Sabalo is a more harsh environment for the bugs, owing to intense substrata redistribution processes during spates.

Nymphs and adults of the vestigially-winged bug, Limnocoris insularis Champion, move upstream against the current, both in the wet and dry seasons. Adults can recolonize the two streams by moving in from the Puerto Viejo River (a 6th-order river into which both streams flow). Population densities of the animals are low in the Sabalo because the animals do not recruit well there and because they are also washed out during spates. Population densities are high in the Sura. The animals can recruit there and they are not washed out during flooding.

Individuals of the second species, $C$. latus Usinger, do not move along stream bottoms against the current. Nymphs and brachypterous adults remain stationary or are passively moved downstream with the current. Populations can recruit and disperse in both streams; however, their dispersal abilities are temporally limited because only the winged morph, uncommon except in the dry season, has the ability to colonize upstream sections.
\end{abstract}

Key words: backfloods; Costa Rica; Cryphocricos latus; dispersal; harsh and benign environments; Limnocoris insularis; mark-recapture; reproduction; spates; tropical streams.

\section{INTRODUCTION}

Tropical streams appear to contain more species of insects than do temperate streams (Fittkau 1964, Bishop 1973, Stout and Vandermeer 1975), although the body of literature on aquatic insects in tropical streams still remains meager. There is one group of aquatic insects that is found primarily in tropical waters, i.e., species in the family Naucoridae (La Rivers 1971). Not only are the species primarily tropical, but they often numerically predominate in tropical streams in which they are found. Two species were found to be the most common insects in lowland streams at Finca La Selva, Costa Rica. Moreover, their abundances differed, depending on the streams in which they lived. Given their numerical predominance in a community containing many species but few individuals per species, a study was undertaken to ascertain the factors that determined their abundances in two adjacent but hydrologically different streams.

\footnotetext{
${ }^{1}$ Manuscript received 23 August 1979; revised 16 January 1981; accepted 6 April 1981.

${ }^{2}$ Present address: Department of Zoology, Michigan State University, East Lansing, Michigan 48824 USA.
}

Because there are few papers on the ecology of tropical aquatic insects in running waters, primarily descriptive phenomena such as behavior, dispersal patterns, spatial and temporal changes in abundances, and effects of flooding on populations were chosen as the parameters for study, instead of the age-specific reproductive and mortality schedules which are often determined in order to account for spatial and temporal abundances for ecologically studied populations.

Populations of these two creeping water bugs differed, depending on the streams they inhabited. One of the streams, the Sabalo, can be considered a harsher environment than the second stream, the Sura (Table 1). It is in the Sabalo that stream bottoms are scoured and substrata moved appreciable distances during floods; in contrast, the Sura is backflooded and never experiences the harsh conditions associated with spating streams and rivers. Both streams are flooded frequently (15-30 times/yr). The life histories of the bugs are long $(>1 \mathrm{yr})$; one species is primarily and the other exclusively aquatic. They cannot escape severe flood periods by leaving as aerial adults, as sometimes happens for other aquatic insects, but must 
TABle 1. Description of Rio Puerto Viejo, El Sabalo, and El Sura.

\begin{tabular}{|c|c|c|c|}
\hline Characteristic & Puerto Viejo & Sabalo & Sura \\
\hline Channel width (m) & $50-70$ & $5-10$ & $3-6$ \\
\hline \multicolumn{4}{|l|}{ Depths (m) } \\
\hline $\begin{array}{l}\text { Nonfiood periods } \\
\text { Flood periods }\end{array}$ & $\begin{array}{l}0.6-1.2 \\
10.5\end{array}$ & $\begin{array}{l}0.3-0.8 \\
\approx 10\end{array}$ & $\begin{array}{l}0.3-0.8 \\
9\end{array}$ \\
\hline \multicolumn{4}{|l|}{ Origin of channel } \\
\hline $\begin{array}{l}\text { Elevation (m) } \\
\text { River distance: source } \\
\text { to sampling station } \\
(\mathbf{k m})\end{array}$ & $\begin{array}{l}1700 \\
24.3\end{array}$ & $\begin{array}{l}300 \\
9.4\end{array}$ & $\begin{array}{l}100 \\
2.6\end{array}$ \\
\hline Average water temperature $\left({ }^{\circ} \mathrm{C}\right)$ & 21 & 21 & 25 \\
\hline $\begin{array}{l}\text { Scouring levels of stream bottom during } \\
\text { floods }\end{array}$ & $?$ & high & low \\
\hline Maximum-minimum velocities without floods & $48-99 \mathrm{~cm} / \mathrm{s}$ & $28-108 \mathrm{~cm} / \mathrm{s}$ & $24-118 \mathrm{~cm} / \mathrm{s}$ \\
\hline Velocities during floods & $?$ & $>116 \mathrm{~cm} / \mathrm{s}$ & 0 to $-62 \mathrm{~cm} / \mathrm{s}$ \\
\hline Direction of flow during heavy floods & Downstream & Downstream & Upstream \\
\hline Stream bottom at riffles & large rocks, pebbles & $\begin{array}{l}\text { rocks and large } \\
\text { pebbles }\end{array}$ & $\begin{array}{l}\text { some rocks, small } \\
\text { pebbles }\end{array}$ \\
\hline Character of channel & rather eroded & $\begin{array}{l}\text { very eroded on one } \\
\text { side or the other }\end{array}$ & $\begin{array}{l}\text { a few slumps, } \\
\text { vegetation- } \\
\text { covered steep } \\
\text { banks }\end{array}$ \\
\hline
\end{tabular}

respond within the harsh environment. Life history phenomena such as dispersal, behavioral responses to floods, and timing of reproduction were appropriate objects of study to answer the central question: how do populations of two species of creeping water bugs maintain themselves in streams with marked differences in harshness of condition?

\section{Materials ANd Methods}

\section{Description of study area and animals}

Finca La Selva, a biological field station owned and operated by The Organization for Tropical Studies, is in a lowland tropical rainforest $50 \mathrm{~m}$ above sea level at $10^{\circ} 27^{\prime} \mathrm{N}$ and $84^{\circ} 0^{\prime} \mathrm{W}$. Three streams, originating from different watersheds, drain the property. The Quebrada El Sura drains the western quadrat and the Quebrada El Sabalo drains the eastern portion. Both streams empty into the Puerto Viejo River, which courses along the northern boundary of the Finca.

Water heights in all channels can exceed $9 \mathrm{~m}$ above normal levels during major flooding. If the Puerto Viejo is in spate as it passes the mouth of the Sura, the forward velocity of the Sura is reduced. If sufficient water enters the stream, the direction of the Sura's flow reverses, causing the stream to backflood. This backflooding not only allows allochthonous material from distant watersheds to enter, but also reduces normal flow rates during a time when other streams experience spates (accelerated forward velocity and accelerated scouring of stream bottoms). As water recedes and normal flow rates resume in the Sura, fine silt settles on the streamside vegetation and stream bottom. The Sabalo has a steeper gradient and drains a larger area than does the Sura; thus the Sabalo is not backflooded by the Puerto Viejo River. Both this stream and the river experience spates when rains fall in the mountainous watershed areas.

Two species of Central American naucorids, Limnocoris insularis Champion and Cryphocricos latus Usinger, numerically dominate the benthic insect fauna in all three river channels studied. The similar-sized species ( 6 and $8 \mathrm{~mm}$ in length) are in different subfamilies, Limnocorinae and Cryphocricinae (Fig. 1a, b). Two characteristics that differentiate the two species are of ecological importance. Limnocoris insularis is vestigially winged; however, males and females of $C$. latus can be vestigially or fully winged. Second, the two species exhibit different behaviors when they are dislodged from stream bottoms. Individuals of $L$. insularis immediately swim downward until they touch the stream bottom. They then crawl rapidly into recesses and actively move among pebbles. Individuals of $C$. latus will passively drift with the current until they touch a stable surface. Once settled on a pebble or rock, they remain stationary.

\section{Field sampling}

Studies on the two species of naucorids began 14 July 1975 and ended 10 August 1977. Ten stations for sampling bugs and the collection of physical data were selected in each of two streams, the Sura and the Sabalo. Each station was partitioned into three micro- 
sites, one on either side and one in the center of the channel. The farthest downstream stations were 120 $\mathrm{m}$ and $106 \mathrm{~m}$, respectively, from the mouths of these streams. A hiatus of $1700 \mathrm{~m}$ separated the first six from the last four stations in the Sabalo. Two stations were selected in the Puerto Viejo, one near the boat landing for the field station and the other toward the center of the river, bringing the total to 22 sampling stations for intensive work. Additional sampling was done periodically in adjacent areas.

At each microsite, water velocities were recorded using a General Oceanics Digital Flowmeter, Model Number 2030, and dissolved oxygen was recorded with a Yellow Springs Instrument Model 57 oxygen meter. Temperature maxima and minima were recorded in each channel with permanently placed Taylor maximum-minimum thermometers.

Changes in water depths during flooding were recorded in the Sura from numbers painted at half-metre intervals on a cement bridge (at station 4), in the Sabalo by flagging streamside vegetation, and in the Puerto Viejo River by reading fluorescent half-metre markings sprayed onto stairs leading into the river. Field station personnel made rainfall data available.

A. Upstream-downstream movement data.-Markrecapture techniques were used for these studies. On marking days, as animals were collected they were placed in a submersible glass container, and later returned to an aerated tank in the laboratory. They were group-marked according to day with a small dot of rapid-drying lacquer (Testors' Paint) the same day of collection. After drying for $15 \mathrm{~min}$, the animals were returned to aerated water. Marked animals were released within $24 \mathrm{~h}$ of collection either at station 4 in the Sura or at station 7 in the Sabalo. Twenty daygroupings of $L$. insularis were marked and recaptured over three wet and two dry season periods from July 1975 to August 1977, and 13 day-groupings of C. latus were marked and similarly treated from July 1976 to August 1977.

B. Habitat recognition.-Since animals used in mark-recapture experiments were collected at various stations for release at one site, two experiments were performed to test the null hypothesis that individuals of $L$. insularis moving away from a release site were not moving in search of their original sites. First, 164 adults and 73 nymphs of $L$. insularis were collected from three downstream sites in the Sura: stations 1 and 2 and a site between those two stations. The animals were marked according to collection site and then replaced at their original collection site on 17 March 1977. If the animals remained at those sites or moved nonrandomly, the null hypothesis could be rejected. Second, 147 adults and 74 nymphs were collected from stations 1 and 2, marked according to collection site, and released on 29 May 1977 at the site different from the one at which they were collected. In the event that the animals returned to the original
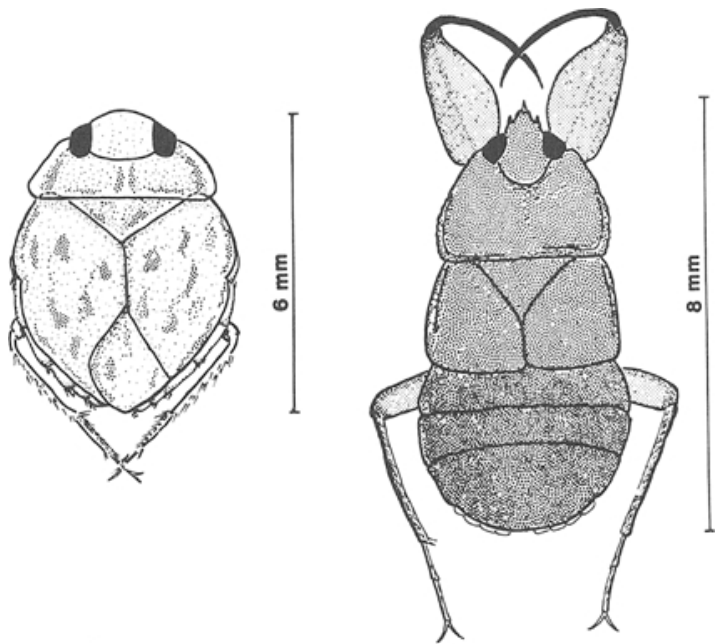

A

B

FIg. 1. The studied two species of naucorids. A. Limnocoris insularis. B. Cryphocricos latus.

collection site and/or moved nonrandomly in another direction, again, the null hypothesis could be rejected.

C. Flooding effects.-Effects of high water on animal abundance and movement patterns were determined by two methods: (1) by collection of animals at all sites before and after floods, and (2) by marking and releasing equal numbers of $L$. insularis $(217,218)$ and equal numbers of $C$. latus $(180,177)$ in both streams just prior to a flood on 10 November 1976. Since densities of $L$. insularis were low in the Sabalo and densities of $C$. latus were low in the Sura, animals of the first species were initially collected from the Sura and animals of the second species were initially collected from the Sabalo.

D. Behavioral data.-Modes of movement for individuals marked and released at both streams were observed under water, using snorkel equipment. Rates at which animals travelled to substrata after being dropped in water were determined in the Puerto Viejo River as well as in standing water in the laboratory. Animals were also observed under laboratory conditions in a $1 \mathrm{~m}$ diameter circular Plexiglas tank. Water was driven by two underwater Teel pumps that forced water around a central core of Plexiglas.

E. Animal abundance data. - Ten handscreen samples, each covering $\approx 1 \mathrm{~m}^{2}$ in area, were collected from each station, three from each side and four from the center. The Puerto Viejo stations were not partitioned. Numbers of individuals per species for each sample were recorded from July 1975 to October 1976, after which period changes in abundances of stage classes for the two species were also recorded. (Sampling of the nymphs and adults in the lower six stations of the Sabalo began 19 February 1977 and ended 10 August 1977.) When animals were not needed for experiments, they were replaced at their station of collection. 


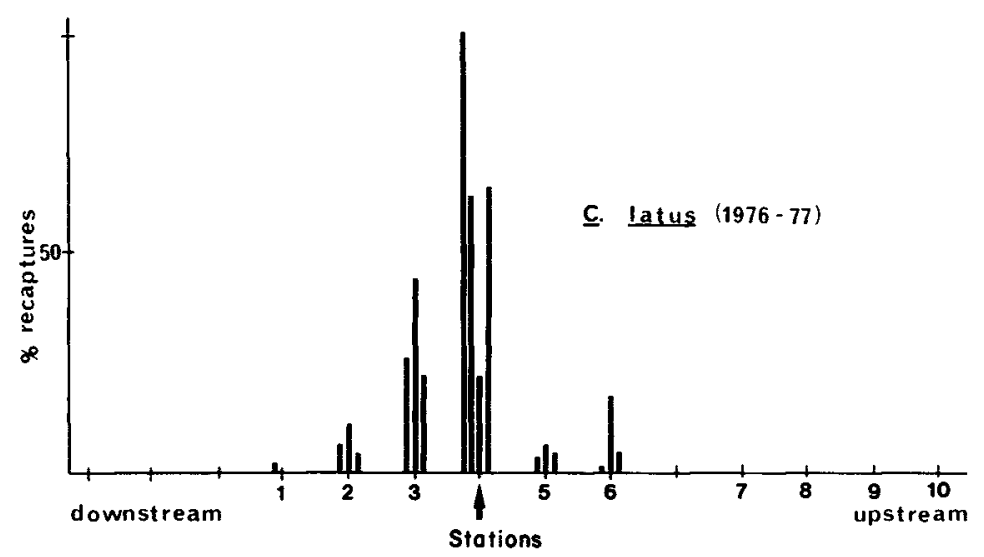

Fig. 2. Movement of $C$. latus in the Sura from 11 August 1976 to 10 August 1977. (Each bar represents proportion captured at a particular station in one of four time periods.)

\section{RESULTS}

\section{A. Upstream-downstream movements}

Cryphocricos latus in the Sura.-Movement patterns for this species in the Sura were determined by marking 1152 individuals in nine sets of group-marking days and recapturing marked animals from 20 July 1976 to 10 August 1977. The overall mark-recapture success rate was $16 \%$. Fig. 2 shows the proportion of marked animals recaptured at each site over four time periods. Over $60 \%$ of the marked animals were recaptured at the release site. Most of the marked animals recaptured away from the site were taken downstream (29\%). A total of $8 \%$ of the recaptured animals were found upstream (stations 5 and 6). They were recaptured 2-8 mo after their initial release. During that time, the Sura had backflooded at least once. Within 1 mo of release, percent recaptures above, at, and below the release site were $2 \%, 76 \%$, and $22 \%$, respectively. Dispersal of the animals away from the release site increased slightly with time, but the general pattern remained the same; i.e., most animals remained stationary, but those that moved away did so in the downstream direction.

Limnocoris insularis in the Sura.-Movement patterns of this species in the Sura were determined by marking 3611 individuals in 10 sets of group-marking days and recapturing marked animals from July 1976 to August 1977. An average of $21 \%$ of marked animals were recaptured over the entire mark-recapture period. Only $35 \%$ of the recaptured animals were taken at the release site (station 4). Of the animals that moved away from the release site, $86 \%$ moved upstream and 14\% downstream (Fig. 3). (Similar results for these animals in 1975-1976 appear in Stout 1978.) Most of the animals that moved upstream were recaptured within $35 \mathrm{~m}$ of the release site, but 29 animals (4\%) were recaptured at station $10,100 \mathrm{~m}$ from the release site. Station $\mathbf{1 0}$ is at the downstream lip of a deep pool, which apparently presented a barrier to these animals.
Above the pool are fast rapids. Upstream from the rapids 30 handscreen samples were taken over a distance of $30 \mathrm{~m}$ on 27 September 1976. An average of 2.80 animals were taken per handscreen sample, fewer than the average of 8.33 for the same day for an equal area below the pool $(t=2.28, P<.01$ for paired observations with unequal variances). These differences in numbers of animals suggest the extent to which the pool and rapids are barriers for individuals of $L$. insularis.

Dispersal of $L$. insularis individuals away from station 4 increased with time, but the direction of movement, whether data came from within 1 mo of release or up to $10 \mathrm{mo}$ after release, showed that individuals of $L$. insularis moved upstream. Percentages of marked animals recaptured in the Sura within 1 mo of each release date are: above, $60 \%$; at, $45 \%$; and below the release site, $6 \%$. The average percentage of all marked animals recaptured over the entire year are: above, $56 \%$; at, $35 \%$, and below, $9 \%$. Ninety percent of the animals that moved away from the release site 1 mo or less after being released, moved upstream.

Mark-recapture data for the dry seasons of 1976 and 1977 as compared to the wet seasons of 1975, 1976, and 1977 show that the pattern is the same: net upstream movement persists for both seasons.

Limnocoris insularis in the Sabalo.-Of the three mark-recapture series done for individuals of this species in the upper six stations of the Sabalo, only 28 animals were marked in the first two series, as the number of animals was very low there $(0.24$ animals per handscreen sample). For the last marking period (8 November 1976) 217 animals were collected in the Sura, marked and then released at station 7 in the Sabalo. A spate occurred in the Sabalo the afternoon of the release day. Only four marked individuals were recaptured, one each at $5 \mathrm{~m}$ below the release site, at the release site, $5 \mathrm{~m}$ above and $20 \mathrm{~m}$ above the release site. 


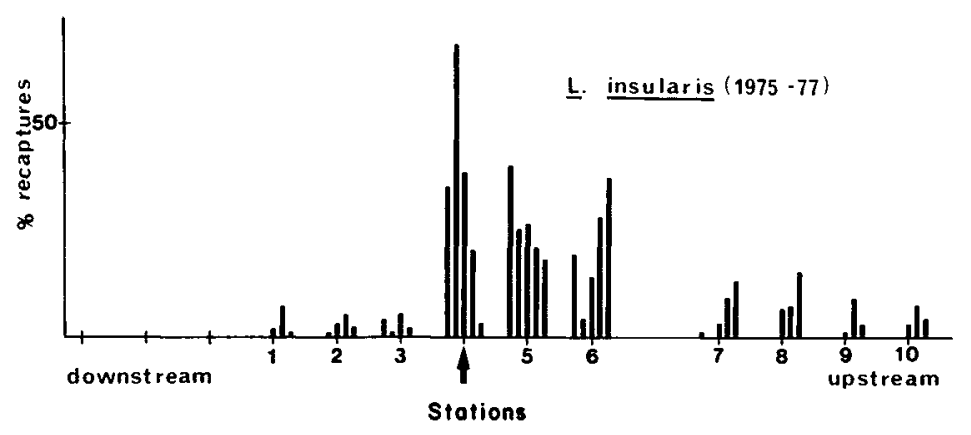

Fig. 3. Movement of L. insularis in the Sura from 16 July 1976 to 10 August 1977. (Each bar represents proportion captured at a particular station in one of five time periods.)

\section{B. Habitat recognition tests for $\mathrm{L}$. insularis}

Because individuals of this species tended to move upstream, homing behavior tests were done to determine whether collection methods affected the results. In the experimental design where nymphs and adults were released at their original capture site, $90 \%$ of the animals that left the release site moved upstream. In the design where animals were released in a station other than their collection site, 95\% that left moved upstream. Homing response behavior for these animals could not be supported by the data (Table 2). The animals tended to move upstream irrespective of their release site. The homing experiments and the general dispersal studies showed similar results: the animals moved upstream against the current (Table 2, Fig. 3).

\section{Effects of flooding}

Physical characteristics such as substratum type and erosion along banks differ in the Sura and the Sabalo (Stout 1981), because during flooding the Sabalo has spates and the Sura is backflooded. In order to determine quantitatively how backflooding and spating affects $C$. latus and $L$. insularis, similar numbers of each species were marked and released in both streams within $24 \mathrm{~h}$ of a flood. A total of two recapture samples were then taken in both streams over the course of an 18-d period. Recapture success for the two species in the Sabalo decreased from previous recaptures. Before the spate, mean recapture success for $C$. latus was $16 \%$ (SE $=4.38, n=$ 3 ); after the spate the success dropped to $1 \%$. The mean recapture success for $L$. insularis before the spate was $24 \%$ ( $\mathrm{SE}=1.95, n=8$ ) and $10 \%$ after the flood. In the Sura, the recapture success for $L$. insularis changed from $21 \%$ ( $\mathrm{SE}=1.17, n=9$ ) to $16 \%$ after backflooding had occurred. Although there were differences in the Sura as well, the differences were less significant than in the Sabalo. It was much more difficult to sample the Sura than the Sabalo after floods, because it took longer for the level of the Sura to fall; thus, handscreen sampling was physically more difficult to do in the Sura, making the likelihood of capturing animals lower.

The effects of floods on animal abundances throughout the study are presented by plotting against time the observed densities obtained from 40 handscreen samples in stations 7 through 10 in the Sabalo and stations 1 through 4 in the Sura (Fig. 4). Flooding had no appreciable effect on the average numbers of individuals collected in the Sura. However, numbers of individuals of $C$. latus in the Sabalo dropped off after two floods, both of which occurred in dry periods (see Fig. 8). Later, during the rainy season of 1977 , changes were not obvious, probably owing to the overall low densities by that time.

TABLE 2. Tests for homing behavior of Limnocoris insularis in the Sura.

I. Animals captured (released at original capture site) Station

\begin{tabular}{|c|c|c|c|}
\hline & & & \\
\hline & 1 & & 2 \\
\hline Moved upstream & 7 & 9 & 3 \\
\hline Moved downstream & 0 & 1 & 1 \\
\hline Remained stationary & 22 & 1 & 21 \\
\hline
\end{tabular}

II. Animals captured (released at station opposite to capture site)

\begin{tabular}{lcc} 
& \multicolumn{2}{c}{ Station } \\
\cline { 2 - 3 } & 1 & 2 \\
\hline Moved upstream & 5 & 13 \\
Moved downstream & 0 & 1 \\
Remained stationary & 9 & 4 \\
\hline
\end{tabular}

III. Comparison between results of mark-recapture data for general dispersal studies and homing behavior tests

Fisher's exact test

\begin{tabular}{lcc} 
& \multicolumn{2}{c}{ Fisher's exact test } \\
\cline { 2 - 3 } & Exact value & $\begin{array}{c}\text { Level of } \\
\text { significance }\end{array}$ \\
\hline Wet season & 0.302 & 0.281 \\
Dry season & 0.581 & 0.675 \\
\hline
\end{tabular}




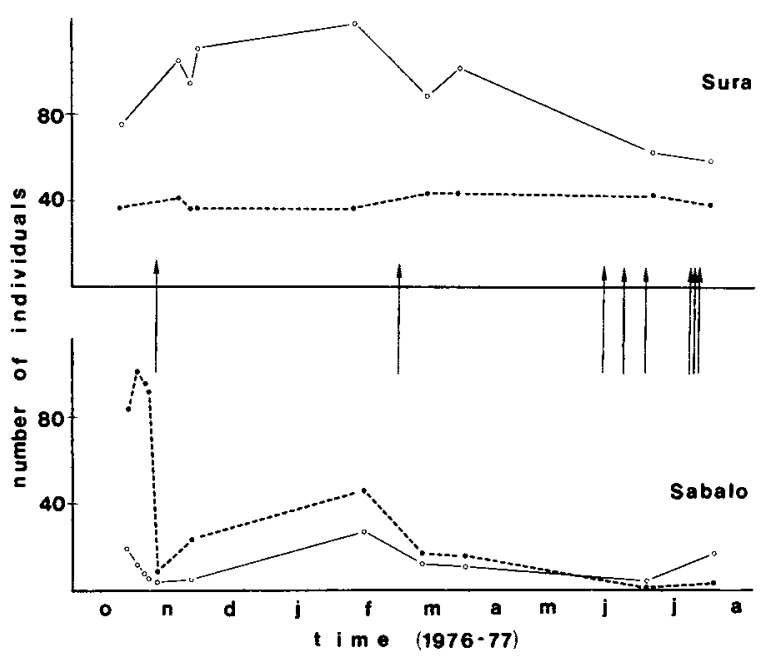

FIg. 4. Effects of backflooding in the Sura and effects of spates in the Sabalo on abundances of $L$. insularis (solid lines) and $C$. latus (broken lines). Vertical arrows mark flood days.

\section{Behavior of the animals}

Individuals of $L$. insularis use swimming and crawling movements to move along the stream bottoms. These animals are difficult to observe on dark substrata of stream bottoms, but they can be observed when placed in tanks containing light-hued aquarium gravel. In aquaria, they move among the pebbles, sometimes going down as much as $10 \mathrm{~mm}$ below the gravel. If food (aquatic insects or frozen brine shrimp) is added to the tank, the bugs will move toward the food, grab and consume it. These animals, if dislodged from either natural or artificial substrata, will quickly swim downward until they once again touch substrata.

Individuals of $C$. latus, rather than actively moving along the substrata, tend to remain along the sides of rocks and attack when prey come to them. In aquaria, the animals seldom move from protected positions on rocks, preferring pitted and dark rather than smooth and light-hued rocks. When food is presented, they wait for the food to approach them before grasping it. The food is consumed without the animals' moving any appreciable distance. If dislodged from natural or artificial substrata, these animals passively float in the water column until water turbulence or their own specific gravity moves them to the substratum. At that time the animals scurry to the side and bottom of the nearest large pebble or rock.

If both species are released into a stream just under the water surface, it takes longer for individuals of $C$. latus to reach a stream bottom $1 \mathrm{~m}$ below the surface (mean time for $C$. latus to reach $1 \mathrm{~m}=20.5 \mathrm{~s}$, $\mathrm{sE}=$ $5.1, n=6$, mean time for $L$. insularis to reach $1 \mathrm{~m}=$ $10.0 \mathrm{~s}, \mathrm{SE}=0.9, n=5$ ). This time differential can be critical when the water is moving rapidly. The difference between movement behaviors for the two species is even more striking when the animals are placed in a bucket of standing water. Both nymphs and adults of $C$. latus float to the bottom; nymphs and adults of $L$. insularis scurry and swim in a downward direction.

\section{E. Changes in abundances of animals}

Limnocoris insularis was always more abundant in the Sura than in any other channel; however, C. latus was more abundant in the Puerto Viejo River than in either of the two streams. Although numbers of this latter species were equally high in the Puerto Viejo and in the upper part of the Sabalo in the wet season of 1976, their numbers fell off in the Sabalo after a spate in October of 1976 and remained low until the termination of the study (Stout 1981).

Changes in abundances over time for both nymphs and adults of both species in the Sura from October of 1976 until August of 1977 are shown in Fig. 5. From February until late June, nymphs tracked adults of their respective species closely; after late June nymphal abundances of both species decreased. Nymphal abundances of $L$. insularis were close to adult abundances in November of the previous year. Although absolute numbers of $C$. latus nymphs were low during October and November 1976, in stations 4 to 6 they increased by November; the pattern of nymphal increase was similar for both species. It appears that both species reproduced throughout the year, although the relative abundances of nymphs to adults increased during the dry season and fell off during the wet season.

The only consistent pattern for both species in the Sabalo was that both species declined in numbers from the beginning of the dry season to the end of the wet season. Nymphal and adult abundances of $C$. latus approximated each other through time, although numbers of both age classes were higher in the dry season in the more upstream stations than in the stations nearer the mouth (Fig. 6). The reverse pattern is true for nymphs and adults of $L$. insularis; there were significantly more adults as well as nymphs in stations 1 through $3(\alpha=.01$, Wilcoxon Matched-Pairs SignedRanks Tests; $T=0$ for each class). The full volume of water flowing down the Sabalo during spates does not flow out its mouth because the banks toward the mouth are not high enough to contain all flood waters. Therefore, excess waters overtop the banks between stations 3 and 4 and flow directly into the Puerto Viejo River. The effects of the Puerto Viejo cause water near the mouth of the Sabalo to be reduced in flow. Both of these factors allow finer sediments to accumulate in pockets in stations 1 to 3 , and it was in such pockets that most of the nymphs of $L$. insularis were found.

In the Sabalo, nymphs of $L$. insularis were in much lower abundances than adults, but nymphal and adult abundances were similar in the Sura. The ratio of adults to nymphs of this species was significantly different in the two streams; however, the adult-to- 

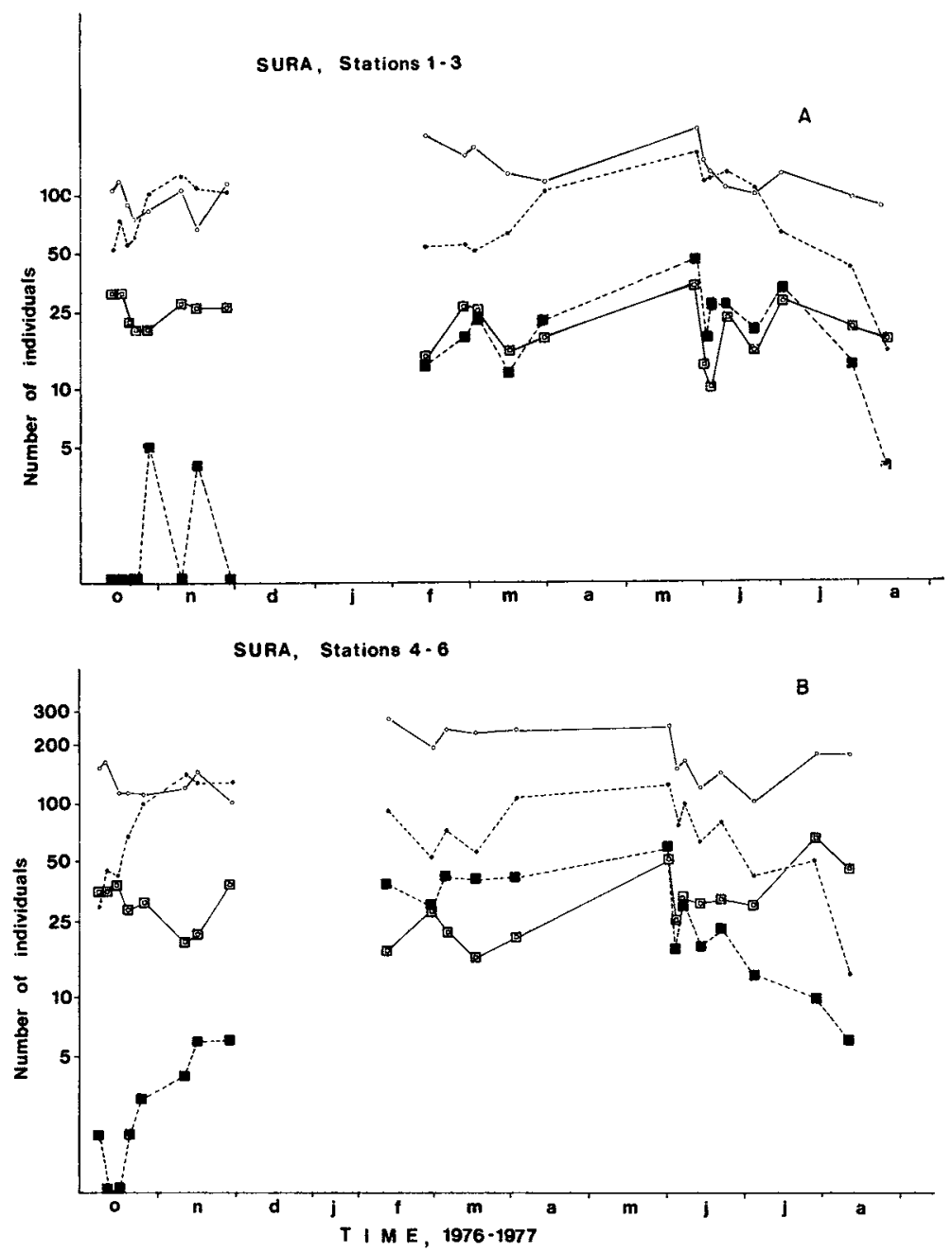

FIG. 5. Nymphs and adults of $L$. insularis (closed circles: nymphs; open circles: adults) and $C$. latus (closed squares: nymphs; open squares: adults) taken from October 1976 to August 1977 at stations $1-3$ (A) and stations 4-6 (B) in the Sura.

nymph ratio for $C$. latus was not significantly different for the two streams (Table 3). Stations 7 through 10 in the Sabalo, $1900 \mathrm{~m}$ from the confluence of the Sabalo and Puerto Viejo River, contained many fewer nymphs of $L$. insularis than did stations 1 through 4 . A maximum of 10 nymphs was taken from 40 handscreen samples in those upper stations; the maximum number of nymphs collected from stations 1 through 4 was 96 . The farther one went upstream, the fewer individuals there were of this species. The pattern was consistent over time.

There was a negative relationship between nymphal abundances of $C$. latus and 1977 average monthly rainfall data in the six downstream stations of the Sabalo $(r=.94, P=.005, n=7)$ and in the six downstream stations of the Sura $(r=.84, P=.037, n=$ 7) for February through August. (See Figs. 5 and 6 for comparison.) No such correlation was found for nymphs of $L$. insularis in either stream.

\section{F. Wing polymorphism, C. latus}

Numbers of individuals of this species are very high in the Puerto Viejo, and data on winged vs. vestigially winged individuals are better known for this river. Numbers of those two morphs appear in Fig. 7. The highest numbers of wingless animals were found in the middle of February. By April, fully winged animals were more common. Both morphs were common during the late dry season months of March through May in 1977, which was also the season when numbers of nymphs were very common. The highest abundances of nymphs coincide with the highest abundances of the winged morph. It is hypothesized that recolonization of upstream areas in streams is effected by the winged morph near the end of the dry season.

\section{Discussion}

Most aquatic insects in midlatitude streams are amphibiotic; in their aquatic juvenile stage they can be 
TABLE 3. Comparison of natural logarithms of numbers of individuals of $L$. insularis and $C$. latus collected from microsites at stations 1 through 6 in the Sura and the Sabalo from February to August 1977. $N=35$; paired $t$ test except where noted.

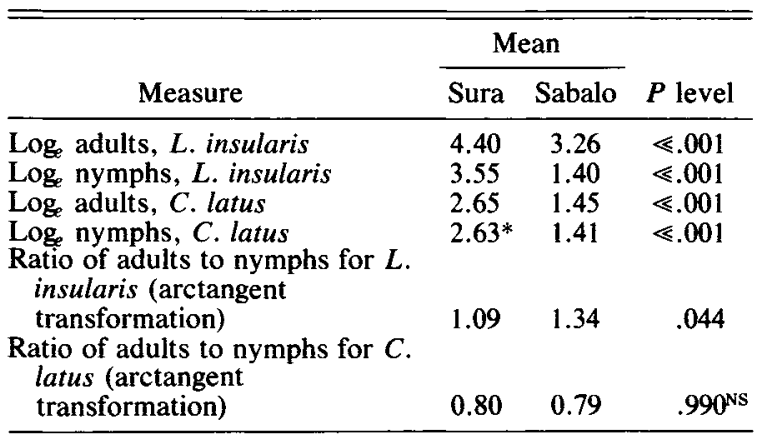

* Mann-Whitney $U$ tests (samples had unequal variances).

washed downstream during spates but they can also recolonize upstream areas as aerial adults (Röos 1957, Waters 1961, 1965, Otto 1971, Müller 1974). Macropterous individuals of $C$. latus are capable of doing that. But brachypterous adults cannot reclaim upstream territory because individuals of this species behave passively if uplifted into the current. The second species, L. insularis, is totally holobiotic; both the juvenile and adult stages are fully aquatic. Only the fact that these animals actively move along stream bottoms and usually go upstream as they forage allows populations of these bugs to counteract catastrophic downstream drifting after floods have subsided.

Some aquatic invertebrates have been shown to move principally upstream at some times during their life histories in midlatitude streams and rivers (Bovbjerg 1952, Minckley 1964, Hazlett et al. 1974, 1979). However, although the animals used in those studies are also holobiotic (snails, scuds, and crayfish), none of them are aquatic insects. Only $L$. insularis, among all the invertebrates whose movement patterns have been studied, moved consistently upstream in all seasons and age classes.

Although $L$. insularis does not have a wide tropical distribution (Honduras south to Costa Rica), it is locally highly abundant at La Selva, relative to other aquatic insects. The streams there are subject to flooding throughout the year. Midlatitude streams also flood, but most floods occur during spring runoff from surrounding higher elevation watersheds. At La Selva, flooding can occur at any time. For example, although precipitation in December is often very low, the highest recorded precipitation occurred in December of 1970 (Fig. 8). These bugs do not escape floods by transforming to aerial adults prior to any predictable floods, nor does the population survive harsh periods by aestivating in a sessile egg stage. The animals can only behaviorally counteract the forces that floods bring. Other very common invertebrates found throughout the year at La Selva are freshwater cray-
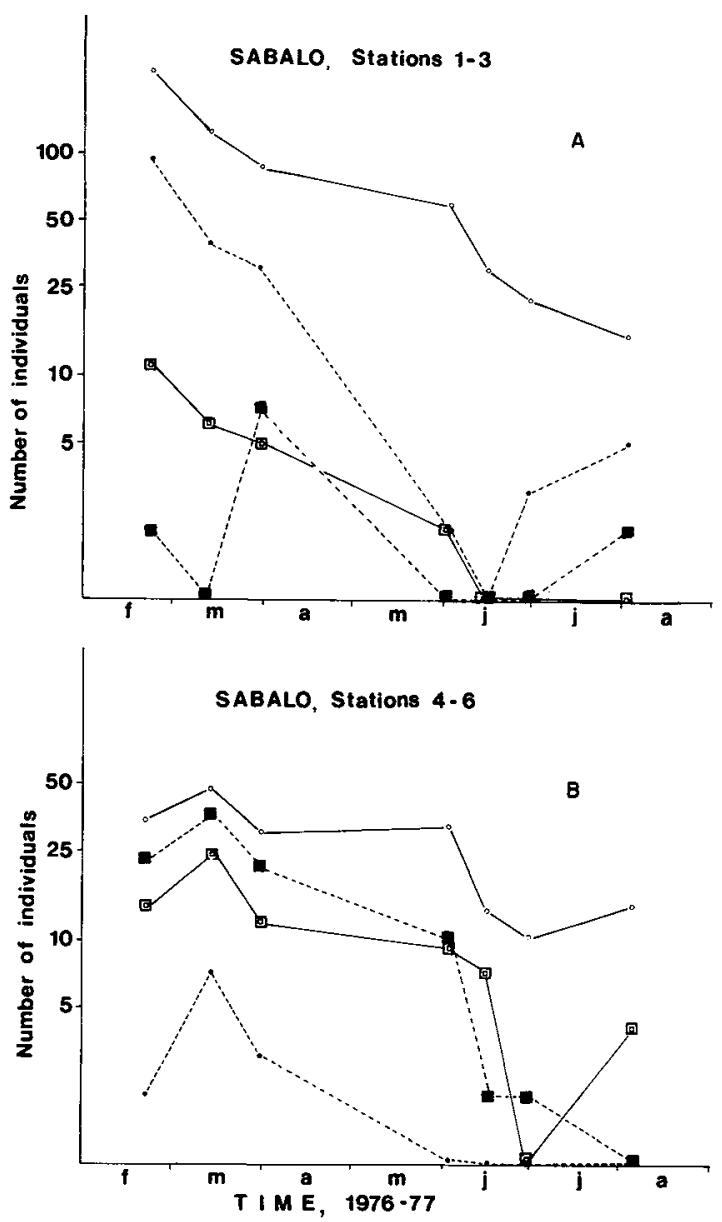

FIG. 6. Nymphs and adults of L. insularis (closed circles: nymphs; open circles: adults) and $C$. latus (closed squares: nymphs; open squares: adults) taken from February 1977 to August 1977 at stations $1-3$ (A) and stations 4-6 (B) in the Sabalo.

fish. They, too, are holobiotic. The commonness of individuals of $L$. insularis, and possibly of the crayfish as well, may be more related to their behavioral movements than to any superior competitive abilities.

Nymphs of both $L$. insularis and $C$. latus were found throughout the year, even though nymphal abundances were higher in the dry season. If, as it

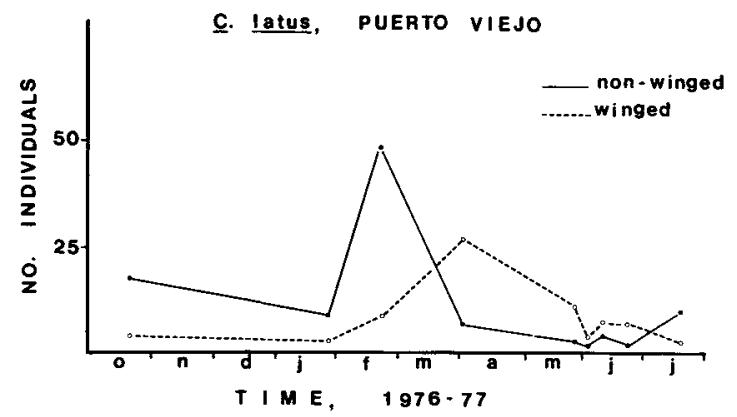

FIg. 7. Abundances of nonwinged vs. winged adults of C. latus in the Puerto Viejo from October 1976 to July 1977. 


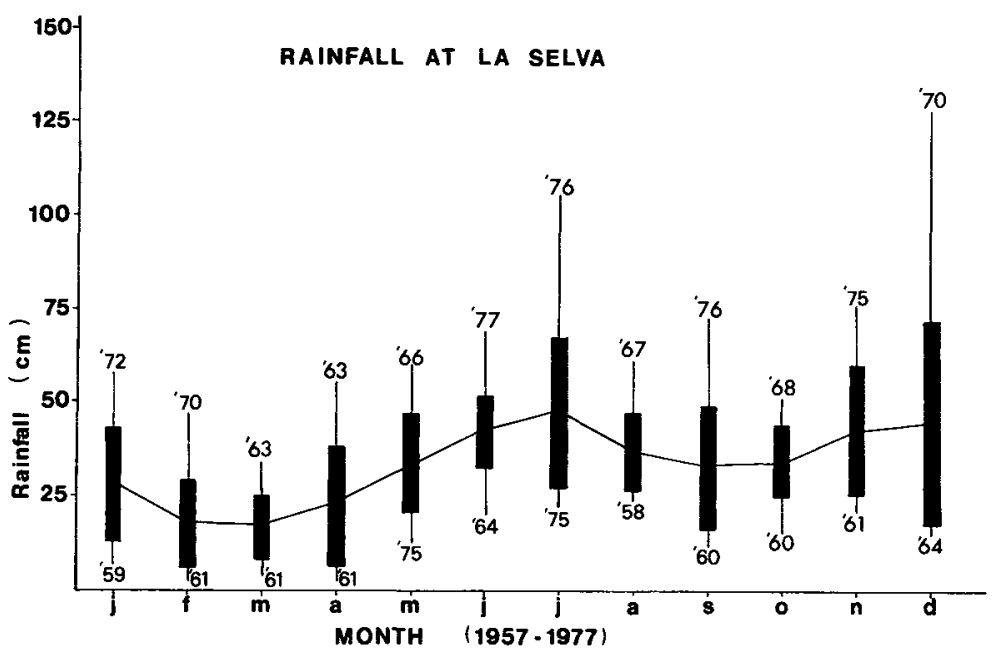

Fig. 8. La Selva rainfall records from October 1957 to August 1977. Monthly means are connected by a line; bars represent \pm 1 SD about the mean; vertical lines represent the range of records for each month, with the years of maximum and minimum amounts indicated (after G. Hartshorn).

appears, both species can reproduce throughout the year, then recolonization after any flood can theoretically be effected, not only by active upstream movement for $L$. insularis or flight by $C$. latus, but through reproductive capabilities as well. The data indicate that $L$. insularis populations may not be able to recruit well in hydrologically harsh streams by reproductive means, even after spates have subsided, because habitats containing finer sediments are rare in those streams. Nymphs of this species were most common among finer sediments (see Stout 1981).

Soils at La Selva, although rich along alluvial plains, are high in clay content (Bourgeois et al. 1972). When rains fall, little is absorbed into the soils, and most of the precipitation flows into the streams. Not only are the effects of precipitation on streams at La Selva unmollified by cold weather (precipitation falling as snow for some months), but high intensity or long duration rains are also unimpeded by a sandy aquifer system. Rainfall for a given month at La Selva varies from year to year (Fig. 8). The response time of precipitation on the streams is short. The behavior of the bugs appears to be sufficiently flexible to allow at least some of the population to withstand the often severe, sometimes unpredictable, and certainly frequent floods in this tropical lowland environment.

\section{ACKNOWLEDGMENTS}

I thank Brian Hazlett, Susan Kilham, Peter Kilham, John Witter, Ken Cummins, and William Cooper for their helpful criticisms and suggestions. This work was supported by a Rackham Pre-doctoral Fellowship (The University of Michigan), an Organization for Tropical Studies Field Studies Award, and an American Association of University Women Pre-doctoral Fellowship.

\section{Literature Cited}

Bishop, J. E. 1973. Limnology of a small Malayan River Sungai Gombak. Monographiae Biologicae 22:1-485.

Bourgeois, W. M., D. W. Cole, H. Riekerk, and S. P. Gessel.
1972. Geology and soils of comparative ecosystem study areas in Costa Rica. Tropical Forestry Series Contribution Number 11, Institute of Forest Products, University of Washington, Seattle, Washington, USA.

Bovbjerg, R. V. 1952. Ecological aspects of dispersal of the snail Campeloma decisum. Ecology 33:169-176.

Fittkau, E. J. 1964. Remarks on limnology of central-Amazon rain-forest streams. Internationale Vereinigung für Theoretische und Angewandte Limnologie, Verhandlungen 15: 1092-1096.

Hazlett, B., D. Rittschof, and D. Rubenstein. 1974. Behavioral biology of the crayfish Orconectes virilis. I. Home range. American Midland Naturalist 92:301-319.

Hazlett, B., D. Rittschof, and D. Rubenstein. 1979. Factors affecting the daily movements of the crayfish Orconectes virilis Hagen (1870) (Decapoda, Cambaridae). Crustaceana, Supplement 5:121-130.

La Rivers, 1. 1971. Studies of Naucoridae (Hemiptera). Memoire II, Biological Society of Nevada, Verdi, Nevada, USA.

Minckley, W. L. 1964. Upstream movements of Gammarus (Amphipoda) in Doe Run, Meade County, Kentucky. Ecology 45: 195-197.

Müller, K. 1974. Stream drift as a chronobiological phenomenon in running water ecosystems. Annual Review of Ecology and Systematics 5:309-323.

Otto, C. 1971. Growth and population movements of Potamophylax singulatus (Trichoptera) larvae in a South Swedish stream. Oikos 22:292-301.

Röos, T. 1957. Studies on upstream migration in adult stream-dwelling insects. Reports of the Institute of Freshwater Research, Drottningholm 38:167-193.

Stout, R. J. 1978. Migration of the aquatic hemipteran Limnocoris insularis (Naucoridae) in a tropical lowland stream (Costa Rica, Central America). Brenesia 14:1-11.

1981. How abiotic factors affect the distribution of two species of tropical predaceous aquatic bugs. Ecology 62:1170-1178.

Stout, R. J., and J. H. Vandermeer. 1975. Comparison of species richness for stream-inhabiting insects in tropical and mid-latitude streams. American Naturalist 109:263280.

Waters, T. F. 1961. Standing crop and drift of stream bottom organisms. Ecology 42:532-537.

. 1965. Interpretation of invertebrate drift in streams. Ecology 46:327-334. 